\title{
Submitting Facility
}

National Cancer Institute

\section{Source}

National Cancer Institute. Submitting Facility. NCI Thesaurus. Code C81294.

The hospital or medical institution that is submitting data or information. 